compounds and $\mathrm{K}_{3} \mathrm{Nd}\left(\mathrm{PO}_{4}\right)_{2}$ are isostructural and crystallize in the monoclinic system with space group $\mathrm{P} 2{ }_{1} / \mathrm{m}$ and Pearson symbol $m P 28$.

Least square refinements gave rise to the above indicated formulas which are consistent with the chemical analysis results. The structure of those vanadates is built up of two independent $\mathrm{VO}_{4}$ tetrahedra sharing edge or corner with $\mathrm{LaO}_{7}$ polyhedron. However, a small difference between the two structures has been observed. Indeed, the $\mathrm{Rb}_{1,435} \mathrm{Cs}_{1,565} \mathrm{La}\left(\mathrm{VO}_{4}\right)_{2}$ structure includes tree larger sites in nine- and ten-coordinate environments, two disordered nine-coordinate $\mathrm{Cs} / \mathrm{Rb}$ positions with occupancies $0.33 / 0.17$ and $0.45 / 0.05$, respectively, and one tencoordinate $\mathrm{Rb}$ position, whereas, in that of $\mathrm{K}_{1,125} \mathrm{Rb}_{1,875} \mathrm{La}\left(\mathrm{VO}_{4}\right)_{2}$ the potassium and rubidium ions are disordered over two large cation positions with nine and ten-neighbouring oxygen (occupancies rates $\mathrm{Rb} / \mathrm{K}$ are $0.33 / 0.17$ and $0.11 / 0.39$, respectively) and one rubidium with eleven-coordinate environments. The $\mathrm{V}-\mathrm{O}$ and $\mathrm{La}-\mathrm{O}$ bond lengths vary from 1.674 to $1.733 \AA$ and from 2.397 to $2.616 \AA$, respectively, in both structures. These values are compatible with those published in the literature for similar vanadates without disorder like $\mathrm{K}_{2} \mathrm{CsLa}\left(\mathrm{VO}_{4}\right)_{2}$.

The infrared and Raman spectra of these two compounds have been established and interpreted. The attribution of vibrationnal spectra was proposed by a study of Raman and infrared spectra. This attribution was confirmed by an analysis in normal coordinates. The simulation of the vibration spectra can be regarded as satisfying since the average deviation between the calculated frequencies and the observed ones is approximately $1,5 \%$.

\section{MS41 P29}

Mechanism of cation migration at high temperature in chabazite Michele Zema, Serena C. Tarantino, Gabriele Montagna Dipartimento di Scienze della Terra, University of Pavia, Italy E-mail: michele.zema@unipv.it

\section{Keywords: zeolite structures; HT XRD; cation distribution}

Chabazite is one of the most widespread natural zeolites, reported from a variety of occurrences (in vugs of plutonic rocks, volcanic rocks and metamorphic rocks). It shows a framework structure consisting of parallel stacks of sixmembered double rings in the sequence ABC. Chabazite is rhombohedral $R-3 m$, but due to some ( $\mathrm{Si}, \mathrm{Al})$ ordering there is a deviation from the trigonal towards the triclinic symmetry [1]. However, this ordering appears to be rather random as due to randomly arranged domains with perfect (Si,Al) ordering. The high temperature structural behaviour of a natural chabazite from Talisker Bay, Skye Island (Scotland), having composition $\left(\mathrm{Ca}_{1.1} \mathrm{Na}_{0.4} \mathrm{~K}_{0.7}\right)\left[\mathrm{Si}_{8.6} \mathrm{Al}_{3.4} \mathrm{O}_{24}\right] \cdot 14.4 \mathrm{H}_{2} \mathrm{O}$, as determined by EMPA and thermogravimetric analyses, has been characterized by means of in situ high temperature singlecrystal X-ray diffraction. Lattice constants have been measured in the $25-700^{\circ} \mathrm{C}$ temperature range at regular intervals and complete XRD data collections have been performed at $\mathrm{T}=25,100,125,175,250,300,425,600^{\circ} \mathrm{C}$. Chabazite is characterized by negative thermal expansion, with a volume reduction of $2.8 \%$ in the $\mathrm{T}$ range investigated; cell volume contraction as a function of temperature is not continuous: (1) from RT up to $100^{\circ} \mathrm{C}$ cell volume decreases linearly as a consequence of linear decreases of both $a_{\mathrm{H}}$ and $c_{\mathrm{H}}$ (hexagonal setting) lattice constants; (2) between 100 and $200^{\circ} \mathrm{C}$ the $c_{\mathrm{H}}$ parameter increases and causes a slightly positive thermal expansion; (3) in the range $200-250^{\circ} \mathrm{C}$ a steep contraction of cell volume is associated to a significant broadening of diffraction profiles; (4) at $\mathrm{T}>250^{\circ} \mathrm{C}$ diffraction profiles are again sharp and narrow, and thermal expansion up to $700^{\circ} \mathrm{C}$ is nil. Structure refinements revealed that at room temperature cations occupy the $\mathrm{C} 2$ and $\mathrm{C} 4$ sites, in which they are partly coordinated by oxygen atoms of the framework and partly by extraframework water molecules, and the $\mathrm{C} 3$ site which can be considered as an aquoion. All these positions are located within the largest cage of the chabazite framework. As long as the dehydration process of chabazite proceeds with increasing temperature, cationic sites become unstable. Cations migrate from $\mathrm{C} 3$ and $\mathrm{C} 4$ towards the $\mathrm{C} 2$ sites as temperature increases from RT to $200^{\circ} \mathrm{C}$. At $\mathrm{T}>250^{\circ} \mathrm{C}$ also the $\mathrm{C} 2$ site is unstable due to the loss of the water molecules participating to its coordination sphere. Therefore cations migrate towards smaller cavities where coordination is assured by oxygen atoms of the framework only. Such mobility is then responsible for the broadening of diffraction profiles observed at this temperature. In particular, cations now occupy the 6-membered double ring ( $\mathrm{C} 1$ site) and a peripheral position within the 8 -membered ring (C5 site). To our knowledge, this latter position had never been reported as a cationic site in earlier works. Reversal experiments demonstrated that the whole process is reversible under the conditions of this study; by decreasing temperature water enters the structure again and cations migrate back to their original positions. The hydration/dehydration process represents then the driving force for the cation migration at high temperature in chabazite.

[1] Mazzi and Galli Jb. Miner. Mh. 1983, H10, 461.

\section{MS41 P30}

Thermoelastic behaviour of $\mathrm{Li}_{2} \mathrm{VOSiO}_{4}$ Serena C. Tarantino $^{\mathrm{a}}$, Michele Zema ${ }^{\mathrm{a}}$, Tiziana Boffa Ballaran ${ }^{\mathrm{b}}$, Paolo Ghigna ${ }^{\mathrm{c}},{ }^{\mathrm{a}}$ Dipartimento di Scienze della Terra, University of Pavia, Italy, ${ }^{\mathrm{b}}$ Dipartimento di Chimica Fisica, University of Pavia, Italy, ${ }^{\mathrm{c} B a y e r i s c h e s ~ G e o i n s t i t u t,}$ Universität Bayreuth, Germany

E-mail: tarantino@crystal.unipv.it

Keywords: high-pressure diffraction; hightemperature diffraction; silicate structures

$\mathrm{Li}_{2} \mathrm{VOSiO}_{4}$ is a synthetic analogue of the mineral natisite, a Na-Ti orthosilicate, The general network of $\mathrm{Li}_{2} \mathrm{VOSiO}_{4}$, with two formulae per unit, is formed by piling up parallel [VOSiO 4$]_{n}{ }^{2-}$ layers of $\mathrm{VO}_{5}$ square pyramids and $\mathrm{SiO}_{4}$ tetrahedra held together by intercalated $\mathrm{Li}$ cations located in distorted octahedral sites. The layer is a 4-connected net with alternating corner-sharing $\mathrm{V}$ and Si polyhedra. Each $\mathrm{V}^{4+}$ square pyramid (hemioctahedron) shares its four equivalent equatorial $\mathrm{O}$ atoms with four different $\mathrm{SiO}_{4}$ groups and the remaining axial $\mathrm{O}$ atom belongs to a vanadyl group. The vanadyl $\mathrm{O}$ atoms alternately point up and down relative to a layer. Structural analogies can be found in several minerals such as sulfohalite, metaautunite and phosphates such as $\alpha-\mathrm{VOPO}_{4}$. All of them have the same topology in the $a b$ projection: corner linked 
(hemi)octahedra and edge-orientated tetrahedra alternate to form layers.

$\mathrm{Li}_{2} \mathrm{VOSiO}_{4}$ is a prototype of two-dimensional $\mathrm{S}=1 / 2$ Heisenberg antiferromagnets on a square lattice, and a wide range of the $J 1-J 2$ phase diagram can be studied by applying pressure, which modifies the frustration ratio $J 2 / J 1$, by changing the bond lengths and angles.

Structural investigations on $\mathrm{Li}_{2} \mathrm{VOSiO}_{4}$ have been carried out in situ by means of single crystal X-ray diffraction techniques at high temperature and at RT high pressure. Structural thermal expansion coefficients in the temperature range $25-500^{\circ} \mathrm{C}$ show positive expansion of lattice constants, which is higher along the $c$ direction, and cell volume. High pressure data at room temperature have been collected up to pressure of $8.5 \mathrm{GPa}$. Unit-cell volume data were fitted with a second-order BM-EOS, simultaneously refined using the data weighted by the uncertainties in V. The bulk modulus is $\mathrm{K}_{\mathrm{T} 0}=99(1) \mathrm{GPa}$, assuming $K^{\prime}=4$. The compressibility of the unit-cell is strongly anisotropic with the $c$ axis approximately four times more compressible than the $a$ axis. Structure refinements revealed that the most relevant modifications occurs essentially at the intercalated ion layer while the $\left[\mathrm{VOSiO}_{4}\right]_{n}{ }^{2-}$ layers are more rigid. Effects of pressure and temperature on $\mathrm{Li}_{2} \mathrm{VOSiO}_{4}$ structure are similar but opposite in sign. This inverse behaviour applies to changes in unit-cell parameters and some polyhedral deformations. The compression and expansion are larger perpendicularly to layering and the most relevant modifications along $c$ as a function of $\mathrm{P}$ and $\mathrm{T}$ depend in larger part on the most compressible structure unit, the Li polyhedron. 